\title{
Coumarin-based iodonium hexafluoroantimonate as an alternative photoinitiator for experimental dental adhesives resin
}

\author{
Peterson Oliveira Boeira' , Carine Tais Welter Meereis ${ }^{1}$, Carlos Enrique Cuevas Suárez ${ }^{1,2}$, \\ Suzanne Mendes de Almeida ${ }^{1}$, Evandro Piva ${ }^{1}$ and Giana da Silveira Lima ${ }^{1 *}$
}

\author{
*Correspondence: \\ gianalima@gmail.com \\ ${ }^{1}$ Biomaterials Development \\ and Control Center (CDC-Bio), \\ School of Dentistry, Federal \\ University of Pelotas, \\ Gonçalves Chaves 457, \\ Pelotas, RS 96015-560, Brazil \\ Full list of author information \\ is available at the end of the \\ article
}

\begin{abstract}
The objective of this study was to evaluate the coumarin-based iodonium hexafluoroantimonate (P3C-Sb) in the polymerization kinetics of an experimental model adhesive resin both in presence of solvent and acid monomer content. A monomer mixture based on Bis-GMA, TEGDMA and HEMA was used as a model adhesive resin. Initially a screening was performed to evaluate P3C-Sb concentrations $(0.25,0.50,1,2,4$ mol\%). Four photoinitiator systems using P3C-Sb at 2 mol\% were evaluated: CQ + EDAB (control), P3C-Sb + CQ, P3C-Sb + EDAB and P3C-Sb + EDAB + CQ. Additionally, the performance of the photoinitiator systems in the presence of ethanol and acidic monomer at four different concentrations $(0,10,20,40$ wt $\%)$ were evaluated. Real-time Fourier transform infrared spectroscopy was used to evaluate degree of conversion (DC) and rate of polymerization (RP). The ternary initiation system P3C-Sb + CQ + EDAB showed similar DC and RP to CQ + EDAB into the model adhesive resin without ethanol, however, in the presence of solvent, P3C-Sb + CQ + EDAB showed the highest polymerization kinetics. An inhibitory polymerization effect was observed when a solvent was introduced to adhesive resin using CQ + EDAB. Polymerization reaction was affected by the presence of acidic monomer irrespective of initiation system used. Adhesive resins with $C Q+E D A B$ and P3C-Sb $+C Q+E D A B$ as initiation systems showed similar DC to $C Q+E D A B$ in presence of acidic monomer. The use of P3C-Sb as a third component of the initiation system seems to be an interesting alternative to improve the polymerization kinetics of simplified dental adhesives which showed to be less sensitive to the residual presence of solvent before photoactivation and it was similar polymerization behavior to CQ + EDAB in presence of acidic monomer.
\end{abstract}

Keywords: Photoinitiator, Degree of conversion, Polymerization rate, Kinetics of polymerization, Dental adhesives

\section{Background}

Developing of simplified dental adhesive systems has been one of the mayor progress of the dental adhesive technology over the last years. Main research has been conducted in order to reduce clinical steps and therefore reducing the technical sensitivity and making the restorative procedure simpler and faster. One-bottle adhesive systems using the 
total-etch technique or self-etching approach consists in complex formulations of different types of monomers (monofunctional, cross-linkers and acidic functional), solvents and initiation system that has caused some problems such as inhibition of polymerization [1-3], reduced shelf-life [2], phase separation and potentially creating a more porous dentin/adhesive interface $[4,5]$. Therefore, these systems has been widely studied in order to improve their adhesive performance [6].

For the polymerization of dental adhesives, a binary photoinitiator system comprising camphorquinone (CQ) and amine is usually used $[7,8]$. The photoinitiator CQ is an $\alpha$-dicarbonyl compound that becomes a reactive specie after light absorption at wavelength range between 400 and $500 \mathrm{~nm}$ [9]. CQ requires a co-initiator, typically a tertiary amine, as $\mathrm{H}$-donor for effective radical generation that can start polymerization process $[10,11]$. Such initiation system can causes yellowing of the dental material because CQ has an intense yellow coloration [12], moreover, amine can undergo yellowing due oxidation over time [13]. Beside this, the combination of CQ and tertiary amine may present additional disadvantages. $\mathrm{CQ}$, as being relatively hydrophobic, has difficulties in initializing the polymerization in the presence of solvents such as ethanol or water, and therefore showed a reduced degree of conversion, rate of polymerization and tensile strength of adhesive resins $[3,7,14]$; in addition, tertiary amine is chemically unstable in acidic material, because a reaction acid-base may occur between the acidic components and basic amines leads to the formation of undesirable quaternary ammonium salts, which reduces the longevity of adhesion to dentin over time $[2,8,15]$.

To address these advantages, alternative initiation systems to $\mathrm{CQ} / \mathrm{EDAB}$ have been investigated in the formulation of dental adhesive resins. The coumarin-based iodonium hexafluoroantimonate (P3C-Sb) is a white colored photoinitiator used in the industry for cationic polymerization with a light absorption spectrum near blue light $\left(\lambda^{\max } 347 \mathrm{~nm}\right)$, which makes it potentially useful for application in dental materials [16]. Previous studies showed that after exposure to a LED $405 \mathrm{~nm}$ wavelength, P3C-Sb acts as an excellent photoinitiator for concomitant cationic/radical photopolymerization of an epoxy/ acrylate blend monomer [17].

Although P3C-Sb can be a promising alternative to the CQ/EDAB system, there is no evidence in the literature regarding the effectiveness of this alternative initiator in radical polymerization of methacrylate monomers used in dental materials. Therefore, this study aimed to evaluate the performance of $\mathrm{P} 3 \mathrm{C}-\mathrm{Sb}$ as photoinitiator, used in combination with $\mathrm{CQ} / \mathrm{EDAB}$, in the radical polymerization of an experimental adhesive resin containing different amounts of solvent and acid monomers. The null hypothesis is that $\mathrm{P} 3 \mathrm{C}-\mathrm{Sb}$ has a similar performance to $\mathrm{CQ} / \mathrm{EDAB}$ system independent of solvent and acidic monomer concentration.

\section{Methods}

Reagents

Bisphenol A glycidyldimethacrylate (Bis-GMA), triethylene glycol dimethacrylate (TEGDMA), 2-hydroxyethyl methacrylate (HEMA) and camphorquinone (CQ) were supplied by Esstech (Essignton, PA, USA). (7-ethoxy-4-methylcoumarin-3-yl) phenyliodonium hexafluoroantimonate (P3C-Sb) was donated by Photo High Technologies (Cracow, Poland). Ethyl 4-dimethylaminobenzoate (EDAB) was purchased from Aldrich Chemical 
(Milwaukee, WI, USA) and absolute ethanol was purchased from Vetec company (Brazil). The acidic monomer 1,3-glycerol dimethacrylate phosphate (GDMA-P) was synthesized as previously described [18]. Structural formula and molecular weight of the initiators evaluated are presented in Table 1.

\section{Formulations}

A model dental adhesive resin was formulated through intensive mixing of $50 \mathrm{wt} \%$ BisGMA, $25 \mathrm{wt} \%$ TEGDMA and $25 \mathrm{wt} \%$ HEMA. In order to determine the optimal concentration, degree of conversion of model dental adhesives containing P3C-Sb $(0.5,1$, $2,4 \mathrm{~mol} \%)+\operatorname{EDAB}(0.8 \mathrm{~mol} \%)$ as photoinitiator system was evaluated. After this initial screening, $2 \mathrm{~mol} \%$ of $\mathrm{P} 3 \mathrm{C}-\mathrm{Sb}$ concentration showed the best performance.

Based on the initial screening concentration, four initiation systems were evaluated

- $\operatorname{CQ}(0.4 \mathrm{~mol} \%)+\operatorname{EDAB}(0.8 \mathrm{~mol} \%)$

- $\mathrm{P} 3 \mathrm{C}-\mathrm{Sb}(2 \mathrm{~mol} \%)+\mathrm{CQ}(0.4 \mathrm{~mol} \%)$

- $\mathrm{P} 3 \mathrm{C}-\mathrm{Sb}(2 \mathrm{~mol} \%)+\mathrm{EDAB}(0.8 \mathrm{~mol} \%)$

- $\mathrm{P} 3 \mathrm{C}-\mathrm{Sb}(2 \mathrm{~mol} \%)+\mathrm{EDAB}(0.8 \mathrm{~mol} \%)+\mathrm{CQ}(0.4 \mathrm{~mol} \%)$

For each initiation system, different concentrations of absolute ethanol and acidic monomer GDMA-P were added: 0, 10, 20, $40 \mathrm{wt} \%$.

To perform the monomer photoactivation, a light emitting diode polywave (Bluephase; Ivoclar Vivadent, Schaan, Liechtenstein), in continuous high power mode (1100 mW/ $\mathrm{cm}^{2}$ ) for $30 \mathrm{~s}$ was used. The intensity of light irradiation was confirmed by a digital power meter (Ophir Optronics, Danvers, MA, USA) at standardized distance of $5 \mathrm{~mm}$ between the fiber tip and digital power meter

\section{Kinetics of polymerization evaluated by RT-FTIR spectroscopy}

The degree of conversion and polymerization rate of the experimental adhesive resins were evaluated in real time using Fourier-transform infrared spectroscopy with a spectrometer (RT-FTIR, Shimadzu Prestige 21 spectrometer, Shimadzu, Japan) equipped with an attenuated total reflectance device composed of a horizontal diamond crystal with a $45^{\circ}$ mirror angle (PIKE Technologies, Madison, WI, USA). A support was coupled

Table 1 Description of initiators evaluated

\begin{tabular}{llll}
\hline Initiators & Abbreviation & Structural formula & Molecular weight \\
\hline Camphorquinone & $\mathrm{CQ}$ & $\mathrm{P3C}-\mathrm{Sb}$ \\
$\begin{array}{l}\text { (7-ethoxy-4-methylcoumarin-3-yl) phenyliodo- } \\
\text { nium hexafluoroantimonate }\end{array}$ & $\mathrm{EDAB}$ &
\end{tabular}


to the spectrometer, which was used to fix the light curing unit in place and standardized the distance at $5 \mathrm{~mm}$ in a parallel position between the fiber tip and the sample. The IR Solution software package (Shimadzu, Columbia, MD, USA) was used in the monitoring scan mode using Happ-Genzel appodization in the range of $1500-1800 / \mathrm{cm}$, a resolution of $4 / \mathrm{cm}$ and a mirror speed of $2.8 \mathrm{~mm} / \mathrm{s}$. With this configuration, one scan was acquired every $1 \mathrm{~s}$ during photoactivation.

Analysis was performed at a controlled room temperature of $23{ }^{\circ} \mathrm{C}\left( \pm 2{ }^{\circ} \mathrm{C}\right)$ and $60 \%$ $( \pm 5 \%)$ relative humidity. In order to avoid light interference, the samples were stored in barrier packages that protect against ambient light and were only dispensed at the time of analysis. The sample $(\sim 3 \mu \mathrm{L})$ was directly dispensed to the diamond crystal and was immediately light cured for 30 s.The degree of conversion was calculated based on the intensity of the carbon-carbon double-bond stretching vibrations (peak height) at $1635 / \mathrm{cm}$ and using the symmetric ring stretching at $1610 / \mathrm{cm}$ from the polymerized and unpolymerized samples as an internal standard. Analyses were performed in triplicate $(\mathrm{n}=3)$. Data were plotted, curve fitting was applied using logistic non-linear regression, and polymerization rate $(\operatorname{Rp}(/ \mathrm{s}))$ was calculated as the degree of conversion at time $t$ subtracted from the degree of conversion at time /t.

\section{Results}

The influence of $\mathrm{P} 3 \mathrm{C}-\mathrm{Sb}$ concentration $(0.25-4 \mathrm{~mol} \%)$ on kinetics polymerization is shown in Fig. 1. P3C-Sb concentrations at 4 and $2 \mathrm{~mol} \%$ showed the higher degree of conversion and polymerization rate, nevertheless $\mathrm{P} 3 \mathrm{C}-\mathrm{Sb}$ adhesives with $4 \mathrm{~mol} \%$ concentration saturates the solution forming a precipitate. Thus, $\mathrm{P} 3 \mathrm{C}-\mathrm{Sb}$ concentration of 2 mol\% was selected to constitute the experimental groups. Lower concentration of P3C-Sb presented lowers degree of conversions, achieving 33, 12 and $4 \%$ for $1,0.5$ and $0.25 \mathrm{~mol} \%$ respectively.

The effect of absolute ethanol concentration on degree of conversation of the model dental adhesive resin using different initiation systems is shown in Fig. 2. Initiation systems $\mathrm{CQ}+\mathrm{EDAB}$ and $\mathrm{P} 3 \mathrm{C}-\mathrm{Sb}+\mathrm{CQ}+\mathrm{EDAB}$ showed similar degree of conversion into the model adhesive resin without ethanol; however, when ethanol was added to dental adhesive resin the ternary initiation system P3C-Sb + CQ + EDAB showed higher degree of conversion when compared to $C Q+E D A B$, irrespective of ethanol concentration. An inhibitory polymerization effect was observed when solvent was introduced to the adhesive resin using CQ + EDAB as initiation system. After $20 \mathrm{~s}$ of photoactivation, the degree of conversion from binary system CQ + EDAB containing 0, 10, 20 and 40\% of ethanol were 49.6, 45.3, 41.7 and $40.8 \%$ respectively. In contrast, the adhesive resin containing ternary photoinitiation system P3C-Sb + CQ + EDAB showed an increase in the degree of conversion with addition of ethanol. Binary photoinitiation systems using P3C-Sb + EDAB obtained lower values of degree of conversion when compared with $\mathrm{P} 3 \mathrm{C}-\mathrm{Sb}+\mathrm{CQ}+\mathrm{EDAB}$ and $\mathrm{CQ}+\mathrm{EDAB}$, while P3C-Sb + CQ demonstrated very low degree of conversion values, $13 \%$, into the model resin adhesive without ethanol. In Fig. 3, the effect of $\mathrm{P} 3 \mathrm{C}-\mathrm{Sb}$ on the rate of polymerization at different ethanol concentrations is shown. The $\mathrm{RP}^{\mathrm{max}}$, independent of the ethanol amount, was higher in the ternary system $\mathrm{P} 3 \mathrm{C}-\mathrm{Sb}+\mathrm{CQ}+\mathrm{EDAB}$. Also, it was observed that the curve inflection point was obtained at an earlier time. 

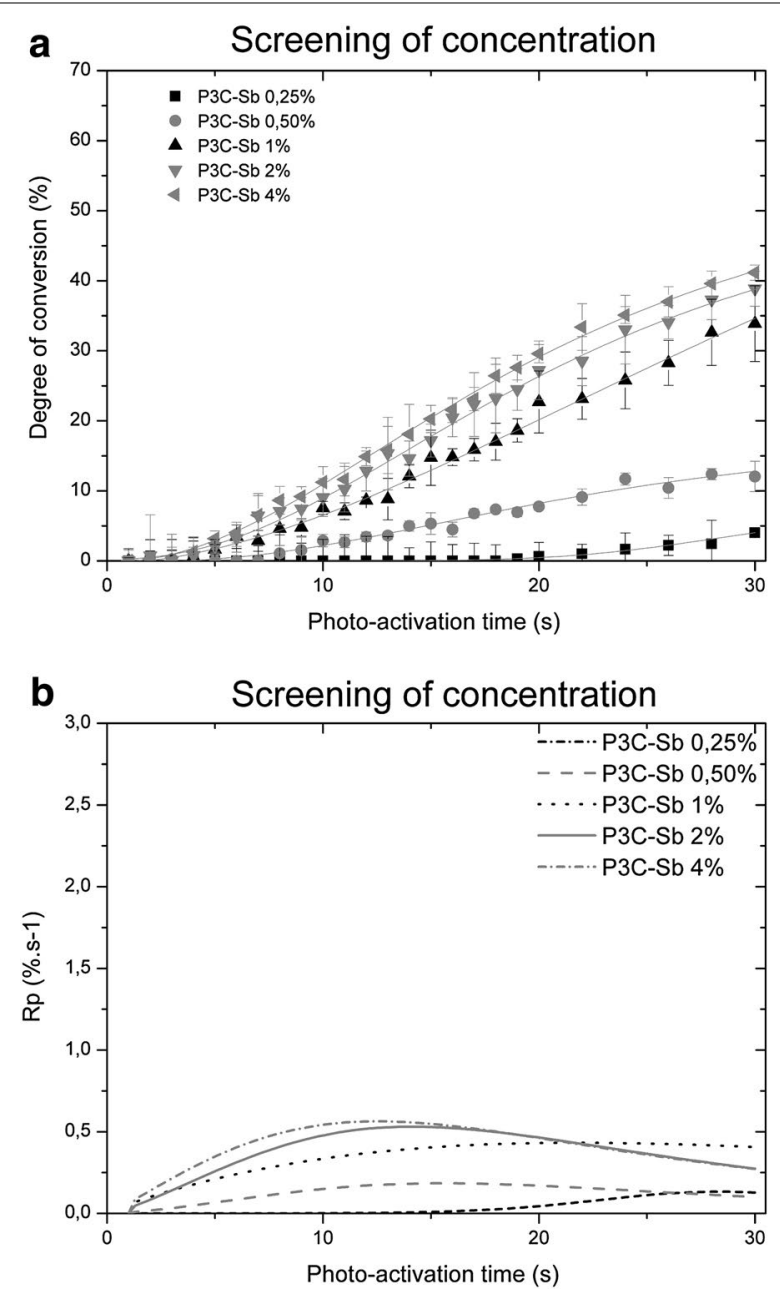

Fig. 1 Degree of conversion (a) and rate of polymerization (b) from experimental adhesive resin with different P3C-Sb concentrations, $(0,25 ; 0,50 ; 1 ; 2$ and 4 mol\%) + EDAB (0.8 mol\%)

The effect of acidic monomer concentration on degree of conversion from the model dental adhesive resin using different initiation systems is shown in Fig. 4. An inhibitory polymerization effect was observed when $40 \%$ of acidic monomer was introduced to the adhesive resin irrespective of initiation system used. Adhesive resins with CQ + EDAB and $\mathrm{P} 3 \mathrm{C}-\mathrm{Sb}+\mathrm{CQ}+\mathrm{EDAB}$ as initiation systems showed similar degree of conversion irrespective of acidic monomer concentration. In Fig. 3, the effect of $\mathrm{P} 3 \mathrm{C}$-Sb on the rate of polymerization at different acidic monomer concentrations is shown. The RP ${ }^{\max }$ for adhesive resin without acidic monomer (GDMA-P 0\%) was higher in the ternary system $\mathrm{P} 3 \mathrm{C}-\mathrm{Sb}+\mathrm{CQ}+\mathrm{EDAB}$. Also, it was observed that the curve inflection point was obtained at earlier time. The $\mathrm{RP}^{\mathrm{max}}$ was affected by the amount of GDMA-P added in adhesive resin irrespective of initiation system used; rate of polymerization values found were similar for CQ + EDAB and P3C-Sb + CQ + EDAB in lower (10\%) and higher (40\%) GDMA-P concentration. 

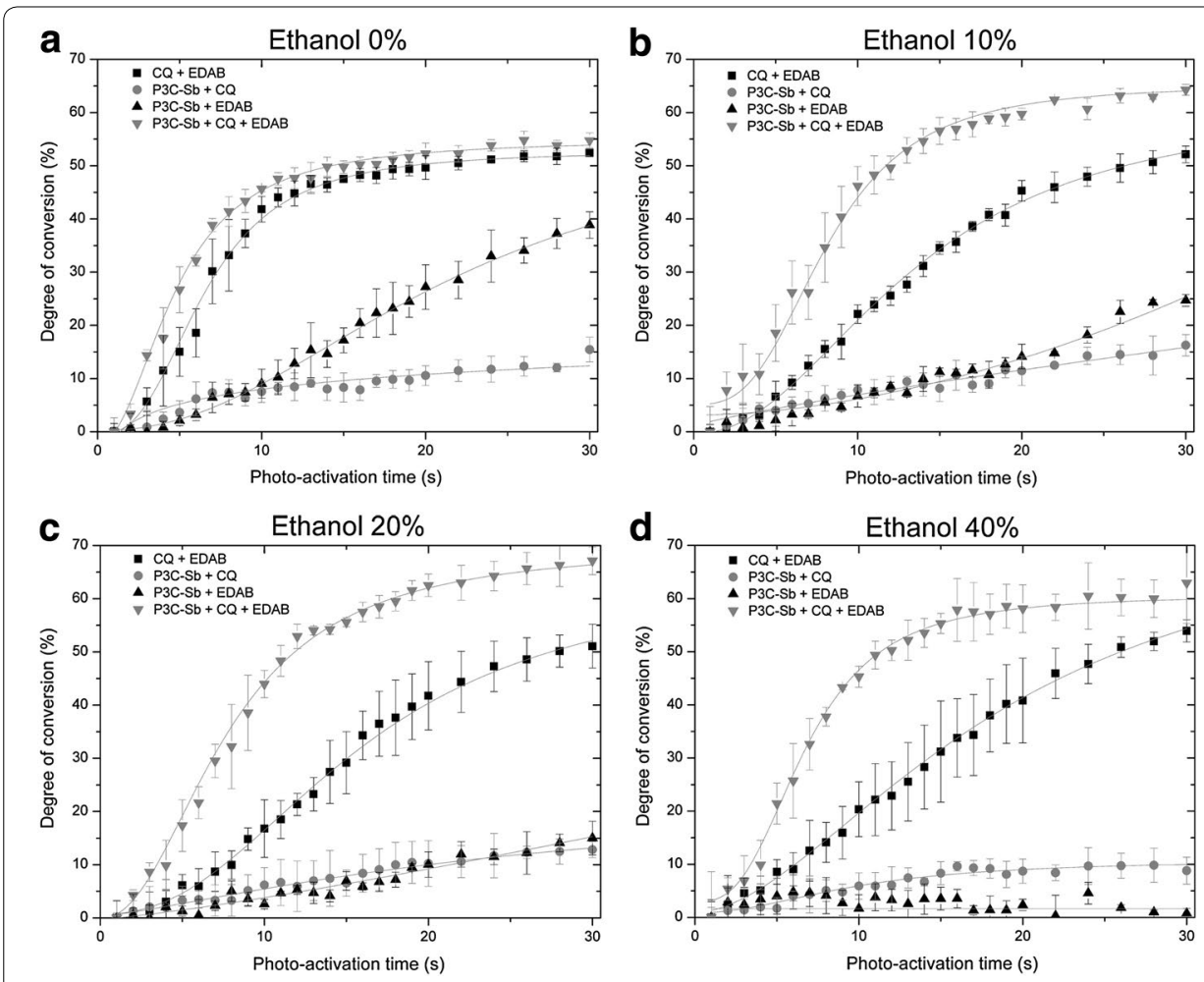

Fig. 2 Effect of the P3C-Sb on the degree of conversion over photoactivation time in each ethanol concentration (a ethanol 0\%; b ethanol 10\%; c ethanol 20\%; d ethanol 40\%)

\section{Discussion}

Traditional CQ/amine system used to the free-radical polymerization of dental adhesives presents some drawbacks and studies on alternative photoinitiator systems remains being necessary, especially when simplified adhesive techniques are used. The present study characterized the polymerization kinetics of the P3C-Sb photoinitiator when used as part of a binary and ternary photopolymerization system. The use of alternative initiator was proposed in an attempt to improve the polymerization reaction from model simplified dental adhesives both in the presence of solvent or acidic monomers. The use of ternary photoinitiator systems formulated with CQ + EDAB + P3C-Sb improved the overall polymerization kinetics of model dental adhesive in the presence of solvents and showed similar degree of conversion to $\mathrm{CQ}+\mathrm{EDAB}$ in the presence of acidic monomer. Thus the null hypothesis was partially rejected.

P3C-Sb was used in two different binary photoinitiation systems, one as a CQ coinitiator $(\mathrm{P} 3 \mathrm{C}-\mathrm{Sb}+\mathrm{CQ})$ and other as a photoinitiator in combination with a tertiary amine (P3C-Sb + EDAB). For both cases, low degree of conversion and polymerization rates values were achieved. The conversion of methacrylate monomers is an important parameter to determine the final properties of the resin material. The presence of unpolymerized monomer can make the material more susceptible to hydrolytic degradation, leading to a poor durability $[3,7,8]$. In addition, higher polymerization rates decrease the time required for photo-activation during clinical application. Lower degree of conversion and polymerization rates results of $\mathrm{P} 3 \mathrm{C}-\mathrm{Sb}+\mathrm{CQ}$ photoinitiation system 

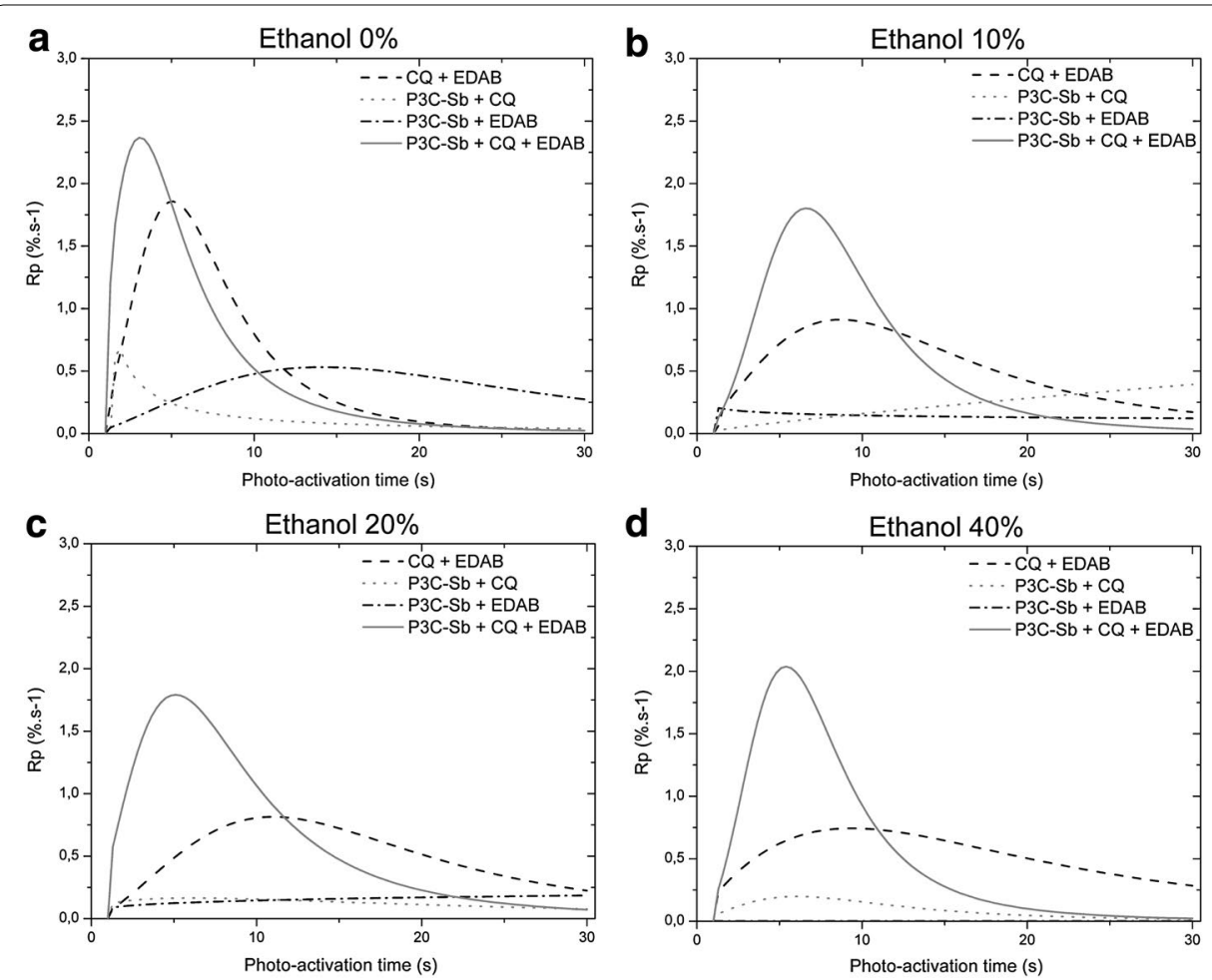

Fig. 3 Comparison between the rate of polymerization from binary and ternary photoinitiator systems polymerized in different ethanol amounts (a ethanol 0\%; b ethanol 10\%; c ethanol 20\%; d ethanol 40\%)

evidences the importance of a tertiary amine to start a polymerization reaction when CQ is used as photoinitiator. CQ is a type II photo-initiator that needs a second component for effective radical generation. Tertiary amines are very effective in reacting with the excited CQ* species as an $\mathrm{H}$-donor to generate free radicals that can start the polymerization process $[10,11]$.

In regards to $\mathrm{P} 3 \mathrm{C}-\mathrm{Sb}+\mathrm{EDAB}$ system, an improvement in polymerization reaction when compared with $\mathrm{P} 3 \mathrm{C}-\mathrm{Sb}+\mathrm{CQ}$ system could be observed, however, lower $\mathrm{C}=\mathrm{C}$ conversion and polymerization rate than $\mathrm{CQ}+\mathrm{EDAB}$ system were obtained. Coumarin-based iodonium hexafluoroantimonate (P3C-Sb) has the extinction coefficient at $365 \mathrm{~nm}$ on level of $75 \%$ of that at the peak maximum located at $345 \mathrm{~nm}$ [16], hence the absorptions levels at visible light wavelength to photolysis of phenyl radicals $\mathrm{Ph}^{*}$ and cleavage of the $\mathrm{C}-\mathrm{I}$ bond through blue light is possible. Previous studies showed that after exposure to an LED $405 \mathrm{~nm}$ wavelength, P3C-Sb appeared as an excellent photoinitiator for concomitant cationic/radical photopolymerization [17]. The wavelength range absorption of the initiators in relation to the curing unit used could also have influenced adhesive resins efficiency. In this study, even a polywave LED unit (Bluephase) that emits light in the wavelength range of 380-515 nm [9] was chosen to adequately activate the both photoinitiators used, absorption range of CQ (400-500 nm) [9], and P3C-Sb (270-390 nm) [16].

Although simplified adhesives have lower sensibility-technique, incomplete volatilization of the solvent can trigger a poor polymerization [19-21]. The excess solvent residual during the in situ polymerization may compromise the mechanical properties of 

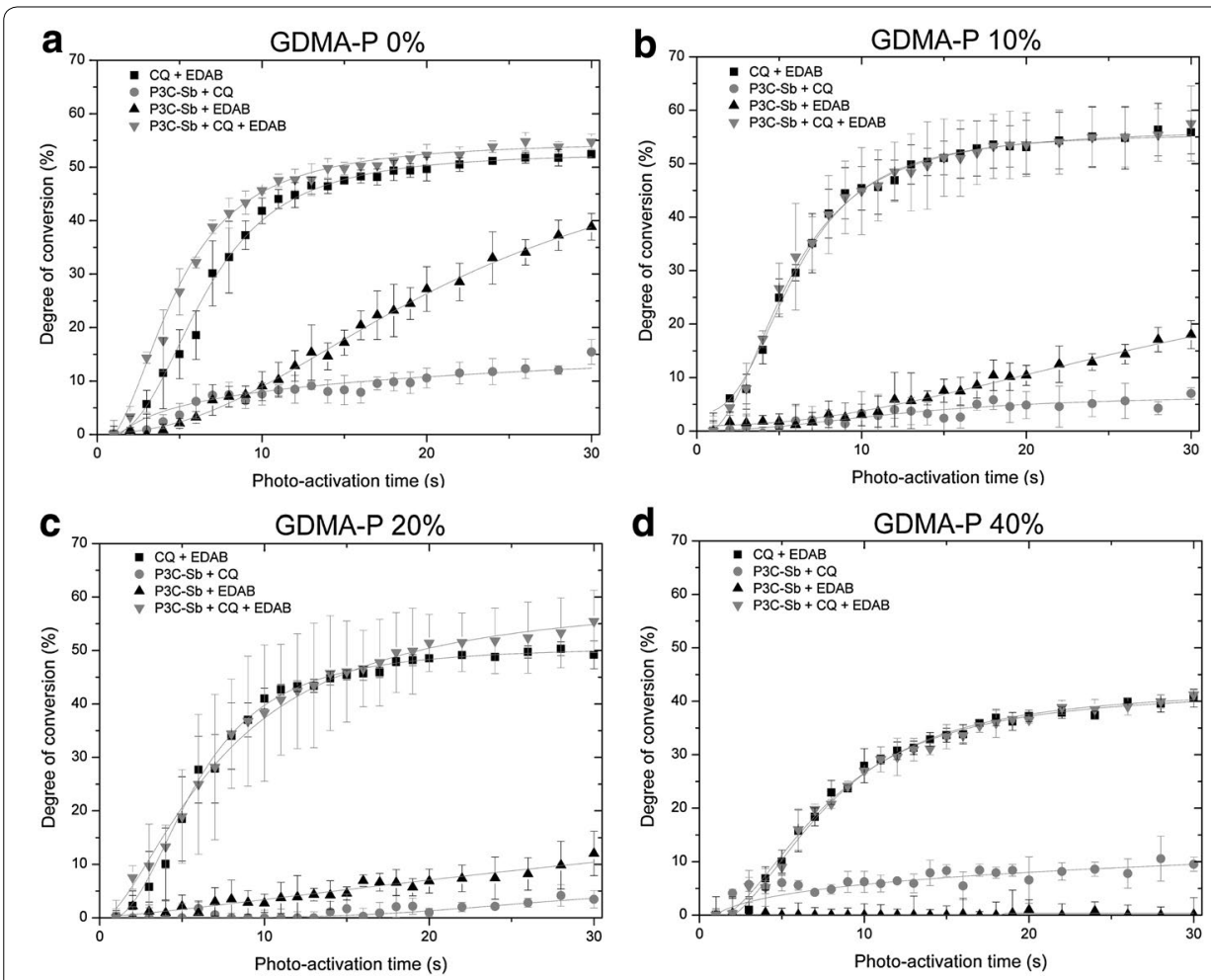

Fig. 4 Effect of the P3C-Sb on the degree of conversion over photoactivation time in each acid monomer (GDMA-P) concentration (a GDMA-P 0\%; b GDMA-P 10\%; c GDMA-P 20\%; d GDMA-P 40\%)

polymer and therefore, the quality of the bonding interface [7, 21]. Figures 2 and 3 demonstrates the effect of the solvent as a retarding agent for the polymerization reaction in photoinitiation binary systems. Irrespective of ethanol concentration, $C Q+E D A B$ showed a slower polymerization and the curve inflection point was obtained at a longer time. It can be theorized that, as the solvent amount increases, the photoinitiator and the density of double-bond terminations in the system, and as a result the reactivity, decreases, explaining the inhibition of the polymerization process [3]. Also CQ, as being relatively hydrophobic, has difficulties in initializing the polymerization in the presence of solvents [3, 14]. Despite this inhibition effect, similar final degree of conversion values was obtained. This phenomena occurs due that the polymerization reaction from monomer and solvent mixtures displays a larger mobility in the environment, which is favorable to a slower onset of gelation and vitrification [22].

One bottle self-etch adhesives contain acidic monomers that simultaneously etch and prime the dental substrate [18]. However, it was previously described that these type of monomers are less reactive than unmodified methacrylate, which yields slower polymerization rates [23]. Acidic monomers also increases the hydrophilicity of the material [24], which can increase the percentage of solvent retained in ethanol-based mixtures even after air-drying evaporation [25]. Figures 4 and 5 shows that higher concentrations of GDMA-P acidic monomer affect the RP ${ }^{\max }$ irrespective of initiation system used. In conditions of acidity, polymerization is affected by the acidic moieties because tertiary amines of the photoinitiation system are neutralized [2]. 

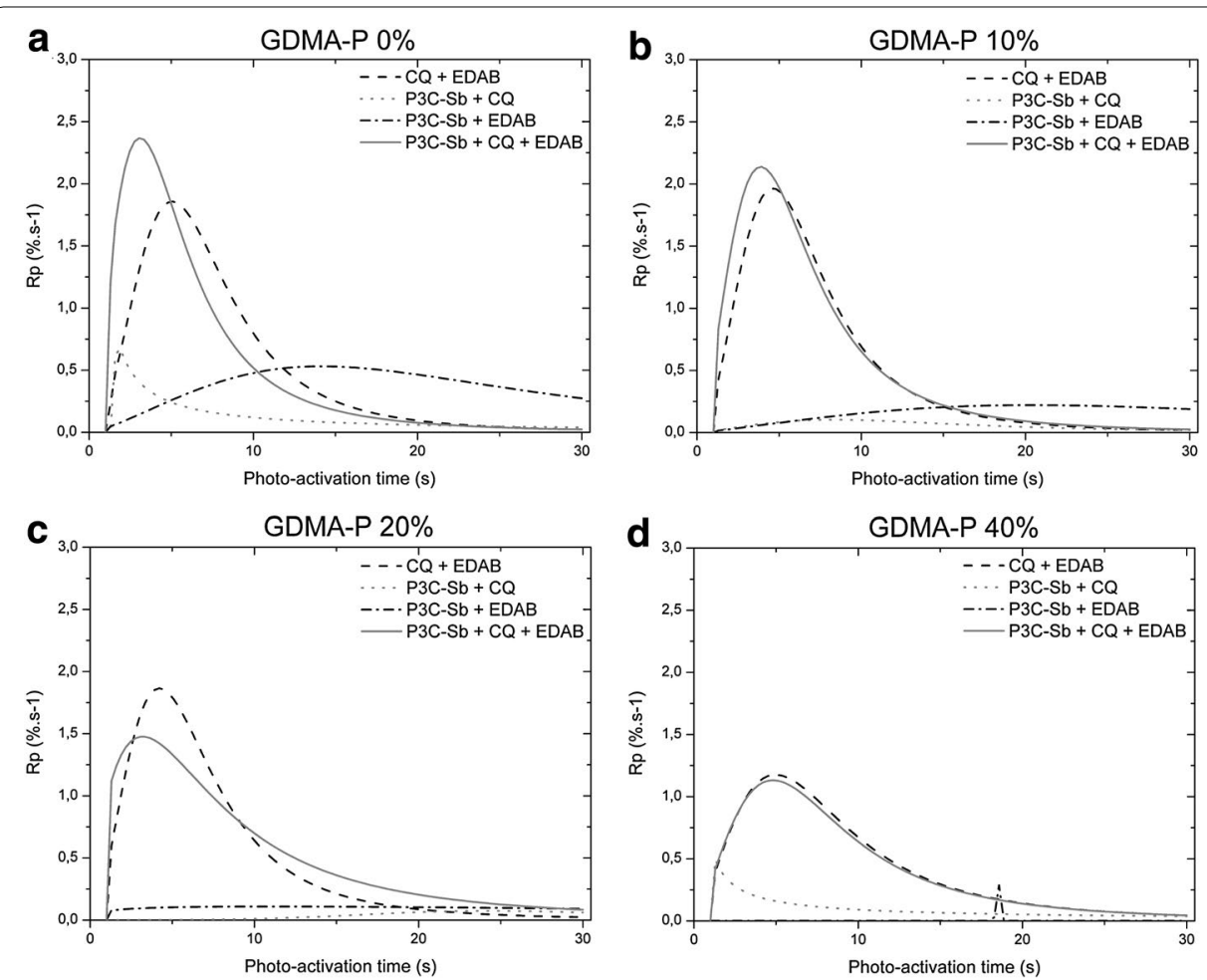

Fig. 5 Comparison between the rate of polymerization from binary and ternary photoinitiator systems polymerized in different acid monomer (GDMA-P) amounts (a GDMA-P 0\%; b GDMA-P 10\%; c GDMA-P 20\%; d GDMA-P 40\%)

An alternative to enhance methacrylate polymerization is the use of ternary photoinitiator systems CQ + EDAB + P3C-Sb. The use of a ternary photoinitiator system, composed of a dye (CQ), an amine (EDAB), and an coumarin-based onium salt (P3C-Sb) resulted in a more effective initiation system than $C Q+E D A B$ in the presence of solvent and showed similar degree of conversion to $C Q+E D A B$ in the presence of acidic monomer. The inhibition effect due the presence of solvent observed in binary systems, was lower for ternary systems. Moreover, some commercial solvent-based dental adhesives have water as co-solvent besides the dentin moisture, which potentially would be an additional challenge to evaporation and in situ polimerization. Previously studies reported an improvement in polymer properties when an iodonium salt is used as part of the photoinitiation system [3,26]. It has been suggested that onium salts acts as a catalyst, decreasing the activation energy of the photoinitiation and therefore, reducing the photoactivation times necessary to achieve optimal polymerization parameters [3]. P3C$\mathrm{Sb}$ presents a good solubility with the methacrylate monomers used in the formulation of model dental adhesives and its introduction in the photoinitiator system provided a significant increase in polymerization kinetics. Their addition as a photoinitiator and a polymerization reaction catalyst with an hydrophilic character could avoid the occurrence of phase separation and decrease polymerization inhibition by residual organic solvents. Thus, materials that show a more stable initiation system in acidic media are expected. A possible synergistic effect of solvent/acidic monomer in the presence of 
P3C-Sb should be added in further studies. Although the results show that P3C-Sb yields improved polymerization reaction with increasing solvent content, it does not mean that residual solvent is not a concern. Since, even after long air-drying, a significant amount of residual solvent is kept in the monomer [25] and it may affect various other important aspects related to dental adhesion. In addition the effect of a higher degree of conversion on the mechanical properties of a polymer is directly related with bond strength. Thus, the use of coumarin-based onium salt as a third component in the photoinitiation system appears to be an interesting alternative to improve the degree of conversion and performance of dental adhesive polymers. Such alternatives photoinitiators systems may represent new perspectives for development of dental materials; therefore, more studies should be conducted to investigate the behavior and applicability of this initiation system, regarding biological, optical and physic-mechanical properties.

\section{Conclusion}

The polymerization kinetics of an experimental dental adhesive resin in the presence of solvent was improved by the use of a ternary initiation system containing P3C-Sb. Also, this ternary system had a similar polymerization behavior than CQ + EDAB when evaluated in the presence of acidic monomer. P3C-Sb could be an interesting alternative to improve the degree of conversion and rate of polymerization of simplified dental adhesives. Therefore, more studies should be conducted to investigate the behavior and applicability of this initiation system.

Authors' contributions

POB and SMA conducted the laboratory tests. POB, CTWM and CECS write the manuscript. EP and GSL delineated the experiment and help in the manuscript written. All authors read and approved the final manuscript.

\section{Author details}

${ }^{1}$ Biomaterials Development and Control Center (CDC-Bio), School of Dentistry, Federal University of Pelotas, Gonçalves Chaves 457, Pelotas, RS 96015-560, Brazil. ${ }^{2}$ Dental Materials Laboratory, Academic Area of Dentistry, Autonomous University of the State of Hidalgo, Circuito ex-Hacienda la Concepción Km. 1.5, 42160 Hidalgo, Mexico.

\section{Acknowledgements}

This work was supported by the Conselho Nacional de Pesquisa (CNPq). Authors are grateful to Programa Nacional de Mobilidade Acadêmica (PROCAD) 071/2013 and CAPES/Brazil for the scholarship and Photo High Technologies Co. Ltd for P3C-Sb photoinitiator donation.

\section{Competing interests}

The authors declare that they have no competing interests.

\section{Consent for publication}

All authors read and approved the manuscript.

Received: 24 December 2016 Accepted: 27 December 2016

Published online: 13 January 2017

\section{References}

1. Lima Gda S, Ogliari FA, da Silva EO, Ely C, Demarco FF, Carreno NL, et al. Influence of water concentration in an experimental self-etching primer on the bond strength to dentin. J Adhes Dent. 2008;10:167-72.

2. Meereis CT, Leal FB, Ogliari FA. Stability of initiation systems in acidic photopolymerizable dental material. Dent Mater. 2016;32:889-98.

3. Ogliari FA, Ely C, Lima GS, Conde MC, Petzhold CL, Demarco FF, et al. Onium salt reduces the inhibitory polymerization effect from an organic solvent in a model dental adhesive resin. J Biomed Mater Res B Appl Biomater. 2008;86:113-8.

4. Hashimoto M, Tay FR, Svizero NR, de Gee AJ, Feilzer AJ, Sano H, et al. The effects of common errors on sealing ability of total-etch adhesives. Dent Mater. 2006;22:560-8.

5. Van Landuyt K, De Munck J, Snauwaert J, Coutinho E, Poitevin A, Yoshida Y, et al. Monomer-solvent phase separation in one-step self-etch adhesives. J Dent Res. 2005;84:183-8.

6. Van Meerbeek B, Yoshihara K, Yoshida Y, Mine A, De Munck J, Van Landuyt KL. State of the art of self-etch adhesives. Dent Mater. 2011;27:17-28. 
7. Leal FB, de Souza AT, Piva E, Ogliari F. Sal de lodônio Aumenta a Resistência Coesiva de uma Resina Adesiva Experimental na Presença de Solvente. Polímeros. 2013;23:678-81.

8. Leal FB, Lima GS, Collares FM, Samuel SM, Petzhold CL, Piva E, et al. lodonium salt improves the dentin bonding performance in an experimental dental adhesive resin. Int J Adhes Adhes. 2012;38:1-4.

9. Ely C, Schneider LF, Ogliari FA, Schmitt CC, Correa IC, Lima Gda S, et al. Polymerization kinetics and reactivity of alternative initiators systems for use in light-activated dental resins. Dent Mater. 2012;28:1199-206.

10. Ikemura K, Endo T. A review of the development of radical photopolymerization initiators used for designing lightcuring dental adhesives and resin composites. Dent Mater J. 2010;29:481-501.

11. Leprince JG, Palin WM, Hadis MA, Devaux J, Leloup G. Progress in dimethacrylate-based dental composite technology and curing efficiency. Dent Mater. 2013;29:139-56.

12. Yoshida K, Greener EH. Effect of photoinitiator on degree of conversion of unfilled light-cured resin. J Dent. 1994;22:296-9.

13. Taira M, Urabe H, Hirose T, Wakasa K, Yamaki M. Analysis of photo-initiators in visible-light-cured dental composite resins. J Dent Res. 1988;67:24-8.

14. Cadenaro M, Antoniolli F, Codan B, Agee K, Tay FR, Dorigo Ede S, et al. Influence of different initiators on the degree of conversion of experimental adhesive blends in relation to their hydrophilicity and solvent content. Dent Mater. 2010;26:288-94

15. Tay FR, King N, Suh B, Pashley DH. Effect of delayed activation of light-cured resin composites on bonding of all-inone adhesives. J Adhes Dent. 2001:3.

16. Ortyl J, Popielarz R. New photoinitiators for cationic polymerization. Polimery. 2012;57:510-7.

17. Mokbel H, Toufaily J, Hamieh T, Dumur F, Campolo D, Gigmes D, et al. Specific cationic photoinitiators for near UV and visible LEDs: iodonium versus ferrocenium structures. J Appl Polym Sci. 2015;132.

18. Leal FB, Madruga FC, Prochnow EP, Lima GS, Ogliari FA, Piva E, et al. Effect of acidic monomer concentration on the dentin bond stability of self-etch adhesives. Int J Adhes Adhes. 2011;31:571-4.

19. De Munck Jd, Van Landuyt K, Peumans M, Poitevin A, Lambrechts P, Braem M, et al. A critical review of the durability of adhesion to tooth tissue: methods and results. J Dent Res. 2005;84:118-32.

20. Breschi L, Mazzoni A, Ruggeri A, Cadenaro M, Di Lenarda R, Dorigo EDS. Dental adhesion review: aging and stability of the bonded interface. Dent Mater. 2008;24:90-101.

21. Ye Q, Spencer P, Wang Y, Misra A. Relationship of solvent to the photopolymerization process, properties, and structure in model dentin adhesives. J Biomed Mater Res, Part A. 2007;80:342-50

22. Andrzejewska E. Photopolymerization kinetics of multifunctional monomers. Prog Polym Sci. 2001;26:605-65.

23. Zhang Y, Wang Y. Photopolymerization of phosphoric acid ester-based self-etch dental adhesives. Dent Mater J. 2013;32:10-8.

24. Cramer NB, Stansbury JW, Bowman CN. Recent advances and developments in composite dental restorative materials. J Dent Res. 2011;90:402-16.

25. Yiu CK, Pashley EL, Hiraishi N, King NM, Goracci C, Ferrari M, et al. Solvent and water retention in dental adhesive blends after evaporation. Biomaterials. 2005;26:6863-72.

26. Ogliari FA, Ely C, Petzhold CL, Demarco FF, Piva E. Onium salt improves the polymerization kinetics in an experimental dental adhesive resin. J Dent. 2007;35:583-7.

\section{Submit your manuscript to a SpringerOpen ${ }^{\circ}$ journal and benefit from:}

Convenient online submission

Rigorous peer review

- Immediate publication on acceptance

Open access: articles freely available online

- High visibility within the field

- Retaining the copyright to your article

Submit your next manuscript at $>$ springeropen.com 